\title{
Theory of mind impairment in Huntington's disease patients and their relatives
}

\author{
Déficits en teoría de la mente en pacientes con enfermedad de Huntington y sus familiares \\ Leo BAYLISS ${ }^{1}$, Victor GALVEZ², Adriana OCHOA-MORALES ${ }^{3}$, Mireya CHÁVEZ-OLIVEROS ${ }^{4}$, Yaneth \\ RODRIGUEZ-AGUDELO4, Guillermo DELGADO-GARCIA' ${ }^{1}$, Marie Catherine BOLL ${ }^{5}$
}

\begin{abstract}
Huntington disease (HD) is an autosomal dominant genetic disorder characterized by movement disorders, cognitive impairment, and psychiatric symptoms. Relatives of HD patients experience a great burden as the latter suffer from altered social conduct and deterioration of interpersonal relationships. Theory of mind (ToM) is the ability to attribute mental states (to oneself and others). Deficits in ToM are thought to have a role in the changes in empathy and interpersonal difficulties that HD patients face. Methods: We conducted a cross sectional study to compare ToM task scores of patients with mild to moderate HD, their relatives (spouse or at-risk first-degree relative with a negative gene test) and controls. Individuals with dementia or depression were excluded. The ToM test battery included Spanish versions of the Reading Mind in the Eyes Test (RMET), Happé's Strange Stories (Social and Physical Stories subtests) and the Hinting Task. Results: The series comprised 12 HD patients, 12 relatives and 12 controls. The HD patients showed lower affective ToM scores than controls (RMET 19 [3.5] vs 23.9 [2.7], $p=0.016$ ). Cognitive ToM tasks scores were lower in HD patients than controls as well (Happés Social Stories 9 [2.6] vs 13 [1.9], $p=0.001$; the Hinting Task 13.6 [3.4] vs 17.5 [4.0], $p=0.009$ ). In the Hinting Task, HD relatives had lower scores in than controls (13 [3.2] vs 17.5 [4.0], p = 0.009) and similar scores to controls in the rest of the battery. Conclusion: The HD patients with mild to moderate disease severity and their relatives show ToM deficits.
\end{abstract}

Keywords: Huntington disease; neuropsychological test; dementia.

\section{RESUMEN}

La enfermedad de Huntington (EH) es una enfermedad genética autosómica dominante caracterizada por trastornos del movimiento, deterioro cognitivo y síntomas psiquiátricos. Los familiares de las personas con EH experimentan gran carga dado que los pacientes sufren de conducta social alterada y deterioro de relaciones interpersonales. La Teoría de la mente (ToM) consiste en la habilidad para atribuir estados mentales (a uno mismo o a otros). Se piensa que déficits en ToM tienen un rol en los cambios en empatía y en las dificultades interpersonales que los pacientes con EH enfrentan. Métodos: Condujimos un estudio transversal para comparar el desempeño en puntajes de tareas de ToM en pacientes con EH leve a moderada, sus familiares (pareja o familiar en riesgo con prueba genética negativa) y controles sanos. Se excluyó a sujetos con demencia o depresión. La batería de pruebas de ToM incluyó versiones en español de la prueba de lectura de la mente en los ojos (RMET), Historias Extrañas de Happé (subpruebas Social y Física) y Hinting Task. Resultados: La serie consistió de 12 pacientes con EH, 12 familiares y 12 controles. Los pacientes con EH mostraron puntajes menores de tareas de ToM afectiva que los controles (RMET 19 [3.5] vs 23.9 [2.7], $p=0.016$ ). Los puntajes de tareas de ToM cognitiva fueron inferiores a los controles en los pacientes con EH (Historias Sociales de Happé 9 [2.6] vs 13 [1.9], p = 0.001; Hinting task 13.6 [3.4] vs 17.5 [4.0], p = 0.009). En la Hinting task los familiares de pacientes con EH mostraron puntajes inferiores que los de los controles (13 [3.2] vs 17.5 [4.0], $p=0.009$ ) y puntajes similares a aquellos de los controles en el resto de la batería. Conclusión: Los pacientes con EH con enfermedad leve a moderada y sus familiares muestran déficits en tareas de ToM.

Palabras-clave: Enfermedad de Huntington; pruebas neuropsicológicas, demencia.

Huntington disease (HD) is an autosomal dominant genetic disorder characterized by movement disorders, cognitive dysfunction and psychiatric symptoms ${ }^{1}$.
Theory of mind (ToM) is the ability to attribute mental states (beliefs and feelings) to oneself and others, and to understand that others have beliefs and feelings different

\footnotetext{
${ }^{1}$ Instituto Nacional de Neurología y Neurocirugía Manuel Velasco Suárez, Division of Neurology, Mexico City, Tlalpan, Mexico;

${ }^{2}$ Universidad Panamericana, Escuela de Psicologia, Laboratorio de Neurociencias Cognitivas y Desarrollo, Mexico City, Mexico;

${ }^{3}$ Instituto Nacional de Neurología y Neurocirugía Manuel Velasco Suárez, Division of Genetics and Molecular Biology, Mexico City, Tlalpan, Mexico;

${ }^{4}$ Instituto Nacional de Neurología y Neurocirugía Manuel Velasco Suárez, Department of Neuropsychology and Support Groups, Mexico City, Tlalpan, Mexico;

${ }^{5}$ Instituto Nacional de Neurología y Neurocirugía Manuel Velasco Suárez, Clinical Research Laboratory, Mexico City, Tlalpan, Mexico.
}

Leo Bayliss (iD) https://orcid.org/0000-0003-3286-6741

Correspondence: Leo Bayliss; Instituto Nacional de Neurología y Neurocirugía Manuel Velasco Suárez - Neurology; Insurgentes Sur 3877 La Fama Mexico City Mexico City Mexico City 14269, Mexico; E-mail: leobayliss@gmail.com

Conflict of interest: There is no conflict of interest to declare.

Received 25 February 2019; Received in final form 25 April 2019; Accepted 08 May 2019. 
from one's own ${ }^{2}$. In clinical practice, ToM is evaluated using neuropsychological tasks, and these tasks are further classified as "affective ToM" (evaluates beliefs about feelings) and "cognitive ToM" (evaluates beliefs about beliefs). Affective ToM is thought to be mediated mainly by the ventromedial prefrontal cortex, whereas cognitive ToM appears to be mediated by the prefrontal cortex as a whole ${ }^{3}$. The ToM deficits have been shown to be present in HD in both cognitive and affective modalities ${ }^{4,5,6,7}$.

Relatives of HD patients experience a great burden as the patients suffer from social conduct and interpersonal relationship deterioration ${ }^{1}$. Deficits in ToM are thought to play a role in the changes in empathy and interpersonal difficulties that HD patients face ${ }^{8}$.

\section{METHODS}

We conducted a cross sectional study to compare ToM task scores of patients with mild-to-moderate HD, their relatives (spouse or at-risk first-degree relative with a negative gene test) and unrelated healthy controls.

\section{Participants}

Twelve consecutive HD patients from our outpatient clinic with a confirmed diagnosis by direct mutation analysis of the number of CAG repeats (four males, eight females) were included. The relatives accompanying the HD patients were invited to participate; 12 were included (nine gene-negative atrisk individuals and three spouses). Twelve unrelated individuals were paired by age and education with the HD patients. Clinical and epidemiological data were collected. We excluded individuals with dementia, depression (Center for Epidemiological Studies - depression scale score $>16)^{9}$, or those unable to read or unwilling to give their informed consent. The local research and ethics committees reviewed and approved the protocol. The research project complied with the requirements of the Declaration of Helsinki as revised in Fortaleza, Brazil, 2013. The participants' confidentiality was preserved.

\section{Instruments}

\section{Disease severity and motor dysfunction}

The severity of HD was assessed using the Total Functional Capacity (TFC) scale, which evaluates the ability to work, handle finances, perform domestic chores, live independently and self-care tasks. The TFC categorizes a functionality deficit as mild (TFC $=10-13)$ or moderate $(\text { TFC }=7-9)^{10}$. Motor dysfunction was evaluated with the Unified Huntington's Disease Rating Scale (UHDRS) ${ }^{11}$.

\section{Cognitive status and emotion recognition}

Cognitive status was assessed with the Spanish version of the Montreal Cognitive Assessment (MoCA) ${ }^{12}$. Emotion recognition was evaluated with Pictures of Facial Affection (POFA), a portfolio of faces comprising 56 photographs of different individuals showing an emotion; the presentation of each face lasted 10 seconds on a computer screen ${ }^{13}$.

\section{Affective ToM}

Affective ToM was assessed with the Reading the Mind in the Eyes Test (RMET). This test comprises a portfolio of 36 pictures of a person's gaze associated with a feeling or thought. For each picture the participant chooses one feeling/thought option (out of four) that best fits. A score of 1 is given for correct choices and 0 for incorrect ones ${ }^{14}$. The Castilian Spanish version of the RMET for adults was from the Autism Research Centre website and adapted into Mexican Spanish ${ }^{14}$.

\section{Cognitive ToM}

The Spanish translations of the cognitive ToM tasks: Happés Strange Stories ${ }^{15}$ and the Hinting Task ${ }^{16}$ were used. One researcher (VG) recorded and applied an audio version of cognitive ToM tasks in order to decrease the effect of reading comprehension skills on task performance. Evaluation required the patient to listen to the recorded test version, then answer verbally. Test scoring was performed thereafter by two neuropsychologists (MC, YR). Happës Strange Stories consists of two subsets of tasks: social stories, related to mental states (ToM) and stories related to control of physical events. Answers are scored as zero points if wrong, one point if partially correct and two points if correct; each subtest can be scored from 0 to 16 points $^{17}$. The Hinting Task test includes 10 short stories of situations with an underlying social event. The participant is asked to interpret the event; the item is rated: 0 if incorrect, 1 if additional information facilitates a correct answer and 2 if correct; test scores range from 0 to 20 points ${ }^{18}$.

\section{Statistical analysis}

Descriptive statistics are presented in medians and interquartile ranges, percentages and absolute numbers. Inferential statistics were performed in categorical variables with the chi square test and in quantitative variables with the Friedman test. To test for correlation, Spearman's method was used. Significant differences were considered at $p<0.05$. Computing was performed in $\mathrm{R}$ package version 3.4. Charts were generated in $\mathrm{R}$ using the ggplot2 library.

\section{RESULTS}

This series comprised 36 participants allocated to three groups: $12 \mathrm{HD}$ patients, $12 \mathrm{HD}$ relatives and 12 healthy, unrelated controls. The series comprised young and middle age adults, predominantly women with a median 15.5 (IQR 5) years of education. There was no significant difference among the groups' participant age, proportion of sexes or years of education (Table). 
The HD group functionality, according to the TFC scores, was preserved in seven patients, mildly affected in three and moderately in two. Nine patients had involuntary movements with a median evolution of 6.8 (IQR 6.1) years. Four patients were taking antidepressants and one was also taking olanzapine. The TFC scores correlated positively with the MoCA scores (Spearman's rho $=0.636, \mathrm{p}<0.05$ ) and negatively with the UHDRS (Spearman's rho $=-.789, \mathrm{p}<0.01$ ), (Table).

\section{Neuropsychological assessment}

\section{Montreal cognitive assessment}

The MoCA scores were not significantly different among groups (Table), although 7/12 HD patients presented with mild cognitive impairment (MoCa score $<26$ points). The MoCA scores did not correlate with education across groups (Spearman's rho $=0.08, \mathrm{p}=0.65$ ).

\section{Pictures of facial affection}

The POFA scores among groups showed no differences (Table). No selective emotion recognition deficit was found in HD patients. Whole-series POFA scores showed a positive correlation with scores of the RMET (Spearman's rho $=.472$, $\mathrm{p}=0.003)$.

\section{Theory of mind tasks}

\section{Affective ToM}

The RMET scores were lower in HD patients than those of HD relatives and controls (19 [3.5] vs 24.5 [3.7] vs 23.9 [7.2], $\mathrm{p}=0.016)$ (Table and Figure).

\section{Cognitive ToM}

The HD patients had lower scores than controls in the Happés Social Stories subtest (9 [2.6] vs 12.5 [1.9], $\mathrm{p}=0.001$ ), while Happës Physical Stories scores showed no significant difference among the groups. Happés Social Stories subtest scores negatively correlated with the UHDRS scores (Spearman's rho $=0.753, p=0.005$ ). The Hinting Task scores were significantly lower in HD patients and HD relatives than in controls (13.6 [3.4] vs 13 [3.2] vs 17.5 [4.0], p = 0.009).

Across groups, cognitive ToM tasks and MoCA scores were positively correlated with Happés Social Stories (Spearman's rho $=0.336, p=0.04$ ), Happés Physical Stories (Spearman's rho $=0.328, p=0.04$ ), as well as the Hinting Task (Spearman's rho $=0.516, \mathrm{p}=0.001$ ).

\section{DISCUSSION}

HD patients with mild to moderate disease severity showed impaired performance in affective ToM tasks (RMET) and cognitive ToM tasks (Happës Social Stories and Hinting Task). This finding has previously been reported in HD patients performing related tasks ${ }^{4,5,6,7}$. Because our HD patients had a mild-to-moderate disease and no statistically significant lower MoCA or POFA scores, ToM tasks score may represent an early marker of dysfunction in $\mathrm{HD}^{4,6}$. A previously-reported correlation between RMET and MoCA scores in HD patients ${ }^{7}$ was not replicated in this study. This may be explained by an even lower severity of disease in terms of functionality and motor impairment in our series. These findings need to be confirmed in a larger series, as ToM tasks

Table. Descriptive characteristics of the study groups.

\begin{tabular}{|c|c|c|c|c|}
\hline Characteristic & HD patients & HD relatives & Controls & $p$-value \\
\hline $\mathrm{N}$ & 12 & 12 & 12 & \\
\hline Sex: Female (\%) & $8(67 \%)$ & $7(58 \%)$ & $9(75 \%)$ & 0.694 \\
\hline Age in years, median (IQR) & $42.7(11.3)$ & $44.7(22.3)$ & $37.1(15.8)$ & 0.264 \\
\hline Years of education & $16.0(5.0)$ & $16(6.2)$ & $14.5(7.5)$ & 0.752 \\
\hline TFC Score & $13.5(1.2)$ & & & \\
\hline UHDRS motor score & $12.5(11.0)$ & & & \\
\hline \multicolumn{5}{|l|}{ Neuropsychological assessment } \\
\hline MoCA & $24.5(4.0)$ & $27.0(1.0)$ & $28.5(1.5)$ & 0.079 \\
\hline POFA & $43.5(9.7)$ & $47(10.7)$ & $45.5(5.5)$ & 0.192 \\
\hline \multicolumn{5}{|l|}{ Affective ToM } \\
\hline RMET & $19(3.5)^{\star}$ & $24.5(3.7)$ & $24(2.7)$ & 0.016 \\
\hline \multicolumn{5}{|l|}{ Cognitive ToM } \\
\hline Happé's Strange Stories total & $15.2(6.9)$ & $20.2(5.5)$ & $23.9(7.2)$ & 0.144 \\
\hline Happé’s Social Stories & $9(2.6)$ * & $10.7(2.7)$ & $12.5(1.9)$ & 0.001 \\
\hline Happé’s Physical Stories & $7.2(4.9)$ & $9.2(4.6)$ & $9.9(4.3)$ & 0.132 \\
\hline Hinting Task & $13.6(3.4)$ & $13(3.2)$ & $17.5(4.0)^{\star}$ & 0.009 \\
\hline
\end{tabular}




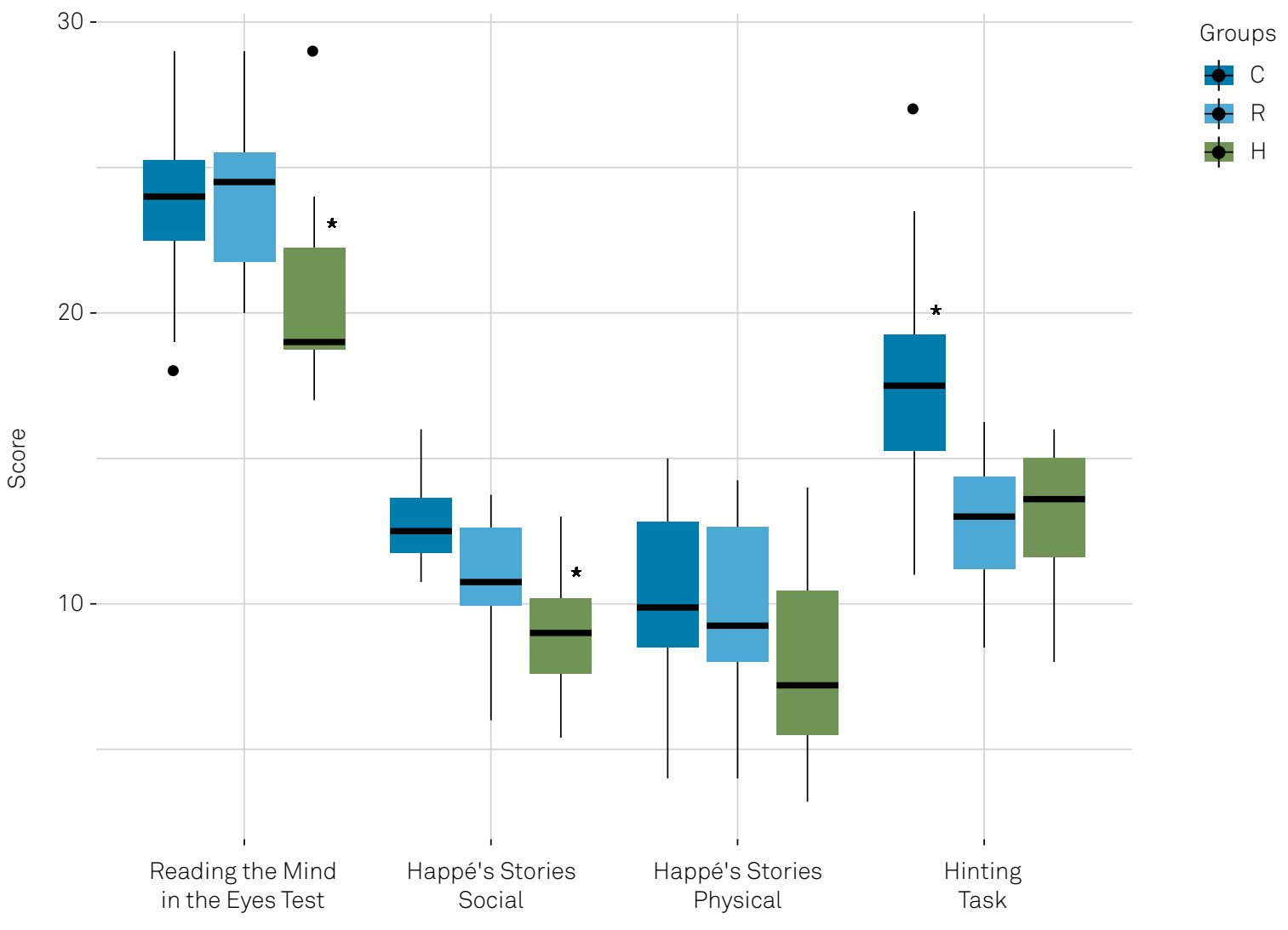

Theory of Mind tasks

Figure. Box plot comparing Theory of Mind (ToM) tasks scores by groups. Statistically significant differences are marked by an asterisk (*). Groups labels: (C) control participant, (R) relative, $(H)$ Huntington's disease.

may have a relevant role in tracking HD progression and correlate with frontal lobe dysfunction ${ }^{3}$.

The HD relatives showed dysfunction in cognitive but not in affective ToM and had a similar performance to controls in the rest of the tests. Similarly, ToM deficits in first degree relatives of schizophrenia patients have been reported ${ }^{4,19}$. The ToM dysfunction may be related either to a genetic trait or an effect of family interaction with HD patients, and requires validation. Limitations of this study are the small sample size and type 1 error, and that the test versions used were not validated translations. Further study in this area may help clarify the particular social difficulties HD families face and may be relevant in genetic counseling ${ }^{20}$.

To our knowledge, this is the first study assessing ToM performance in Latin American HD patients and their relatives. These findings suggest a role of ToM testing in the early cognitive profile and social and family interaction of HD patients and these may parallel those found in schizophrenia and their relatives.

\section{Acknowledge}

The authors would like to thank to all the patients and their families for the cooperation provided.

\section{References}

1. Paulsen JS. Cognitive impairment in Huntington disease: diagnosis and treatment. Curr Neurol Neurosci Rep. 2011 Oct;11(5):474-83. https://doi.org/10.1007/s11910-011-0215-x

2. Premack D, Woodruff G. Does the chimpanzee have a theory of mind? Behav Brain Sci. 1978 Dec;1 (4):515-26. https://doi.org/10.1017/S0140525X00076512

3. Shamay-Tsoory SG, Tomer R, Berger BD, Goldsher D, Aharon-Peretz J. Impaired "affective theory of mind" is associated with right ventromedial prefrontal damage. Cogn Behav Neurol. 2005 Mar;18(1):55-67. https://doi.org/10.1097/01.wnn.0000152228.90129.99
4. Brüne M, Blank K, Witthaus H, Saft C. “Theory of mind” is impaired in Huntington's disease. Mov Disord. 2011 Mar;26(4):671-8. https://doi.org/10.1002/mds.23494

5. Allain P, Havet-Thomassin V, Verny C, Gohier B, Lancelot C, Besnard J, et al. Evidence for deficits on different components of theory of mind in Huntington's disease. Neuropsychology. 2011 Nov;25(6):741-51. https://doi.org/10.1037/a0024408

6. Eddy CM, Sira Mahalingappa S, Rickards HE. Is Huntington's disease associated with deficits in theory of mind? Acta Neurol Scand. 2012 Dec;126(6):376-83. https://doi.org/10.1111/j.1600-0404.2012.01659.x 
Lagravinese G, Avanzino L, Raffo De Ferrari A, Marchese $\mathrm{R}$, Serrati C, Mandich P, et al. Theory of Mind Is Impaired in Mild to Moderate Huntington's Disease Independently from Global Cognitive Functioning. Front Psychol. 2017 Jan;8:80. https://doi.org/10.3389/fpsyg.2017.00080

8. Snowden JS, Gibbons ZC, Blackshaw A, Doubleday E, Thompson J, Craufurd D, et al. Social cognition in frontotemporal dementia and Huntington's disease. Neuropsychologia. 2003;41(6):688-701. https://doi.org/10.1016/S0028-3932(02)00221-X

9. González-Forteza C, Wagner Echeagaray FA, Jiménez Tapia A. Escala de Depresión del Centro de Estudios Epidemiológicos (CES-D) en México: análisis bibliométrico. Salud Ment. 2012;35(1):13-20.

10. Shoulson I, Fahn S. Huntington disease: clinical care and evaluation Neurology. 1979 Jan;29(1):1-3. https://doi.org/10.1212/WNL.29.1.1

11. Huntington Study Group. Unified Huntington's Disease Rating Scale: reliability and consistency. Mov Disord. 1996 Mar;11(2):136-42. https://doi.org/10.1002/mds.870110204

12. Nasreddine ZS, Phillips NA, Bédirian V, Charbonneau S, Whitehead V, Collin I, et al. The Montreal Cognitive Assessment, MoCA: a brief screening tool for mild cognitive impairment. J Am Geriatr Soc. 2005 Apr;53(4):695-9. https://doi.org/10.1111/j.1532-5415.2005.53221.x

13. Ekman P. Friesen. Pictures of facial affect. Consulting Psychologists Press. 1976 [cited 2018 Feb 19]. Available from: https://ci.nii.ac.jp/naid/10011335061/

14. Baron-Cohen S, Wheelwright S, Hill J, Raste Y, Plumb I. The "Reading the Mind in the Eyes" Test revised version: a study with normal adults, and adults with Asperger syndrome or high-functioning autism. J Child Psychol Psychiatry. 2001 Feb;42(2):241-51. https://doi.org/10.1111/1469-7610.00715

15. Pousa i Tomàs E. Measurement of theory of mind in healthy adolescents: translation and cultural adaptation of F. Happè's theory of mind stories 1999. Barcelona: Universidad Autónoma de Barcelona; 2002.

16. Gil D. Fernández-Modamio M, Bengochea R, Arrieta M [Adaptation of the Hinting Task theory of the mind test to Spanish]. Rev Psiquiatr Salud Ment. 2012 Apr;5(2):79-88. Spanish. https://doi.org/10.1016/j.rpsm.2011.11.004

17. Happé FG. An advanced test of theory of mind: understanding of story characters' thoughts and feelings by able autistic, mentally handicapped, and normal children and adults. J Autism Dev Disord. 1994 Apr;24(2):129-54. https://doi.org/10.1007/BF02172093

18. Corcoran R, Mercer G, Frith CD. Schizophrenia, symptomatology and social inference: investigating "theory of mind" in people with schizophrenia. Schizophr Res. 1995 Sep;17(1):5-13. https://doi.org/10.1016/0920-9964(95)00024-G

19. Achával D, Costanzo EY, Villarreal M, Jáuregui IO, Chiodi A, Castro MN, et al. Emotion processing and theory of mind in schizophrenia patients and their unaffected first-degree relatives. Neuropsychologia. 2010 Apr;48(5):1209-15. https://doi.org/10.1016/j.neuropsychologia.2009.12.019

20. Alonso ME, Ochoa A, Sosa AL, Rodríguez Y, Chávez M, Boll C, et al. Presymptomatic diagnosis in Huntington's disease: the Mexican experience. Genet Test Mol Biomarkers. 2009 Dec;13(6):717-20. https://doi.org/10.1089/gtmb.2009.0032 